\title{
Are Your Patients Satisfied? A Systematic Review of Treatment Satisfaction Measures in Psoriasis
}

\author{
Nicole Salame ${ }^{a}$ Lourdes M. Perez-Chada ${ }^{b}$ Sanminder Singh ${ }^{c}$ \\ Kristina Callis Duffin ${ }^{d}$ Amit Garg ${ }^{e}$ Alice B. Gottlieb ${ }^{f}$ John Latella ${ }^{g}$ \\ Joseph F. Merola ${ }^{b, h}$ April W. Armstrong ${ }^{i}$
}

a University of California, Irvine School of Medicine, Irvine, CA, USA; ${ }^{b}$ Department of Dermatology, Harvard Medical School, Boston, MA, USA; ' University of California, Davis School of Medicine, Sacramento, CA, USA; d Department of Dermatology, University of Utah, Salt Lake City, UT, USA; ${ }^{\circ}$ Department of Dermatology, Donald and Barbara Zucker School of Medicine at Hofstra/Northwell, New Hyde Park, NY, USA; ${ }^{f}$ Department of Dermatology, New York Medical College, Metropolitan Hospital, New York, NY, USA; ${ }^{9}$ International Dermatology Outcome Measures (IDEOM), Windsor, CT, USA; hepartment of Dermatology and Department of Medicine, Division of Rheumatology, Brigham and Women's Hospital, Boston, MA, USA; 'Department of Dermatology, Keck School of Medicine of University of Southern California, Los Angeles, CA, USA

\section{Keywords}

Treatment satisfaction - Outcome measures · Psoriasis .

Measurement properties - Treatment satisfaction

measurement instruments · Treatment satisfaction

measures · Patient-reported outcome measures .

Psychometrics

\begin{abstract}
Treatment satisfaction is paramount to the field of dermatology. Treatment dissatisfaction directly impacts patient outcomes and health care delivery. A critical need exists for standardized, validated treatment satisfaction measures in dermatology. Comprehensive evaluation of the performance of treatment satisfaction instruments used in psoriasis is lacking. We sought to critically appraise the literature on measurement properties of treatment satisfaction instruments used in psoriasis. We performed a systematic review to identify treatment satisfaction instruments used in psoriasis and
\end{abstract}

corresponding studies on their measurement properties. We followed the COnsensus-based Standards for the selection of health Measurement INstruments (COSMIN) methodology to inform a best evidence synthesis. Eleven instruments were identified. Six achieved positive content validity ratings, 2 achieved positive reliability and structural validity ratings, and 1 achieved a positive internal consistency rating. The REFlective evaLuation of psoriasis Efficacy of Treatment and Severity (REFLETS) and the Spanish Satisfaction With Treatment of Psoriasis Questionnaire (SSWTPQ) had the highest overall performance. Measurement property data for treatment satisfaction instruments were found to be insufficient in identifying a single best treatment satisfaction instrument for psoriasis. Additional studies are required to better characterize the measurement properties of treatment satisfaction measures and allow for standardized assessments across psoriasis clinical trials and clinical practice.

(c) 2018 S. Karger AG, Basel

\section{KARGER}

(c) 2018 S. Karger AG, Basel
April W. Armstrong, MD, MPH

University of Southern California

1975 Zonal Avenue, KAM 510, MC 9034

Los Angeles, CA 90089 (USA)

E-Mail armstrongpublication@gmail.com 


\section{Introduction}

Treatment satisfaction in dermatology is a fundamental element to patient care that is frequently unexplored. As a predictor of adherence, satisfaction influences treatment optimization and, thus, patient outcomes $[1,2]$. For chronic diseases, treatment satisfaction is an essential driver of disease control [3]. Up to one half of chronically ill patients are estimated to compromise their treatment due to nonadherence [4]. When their clinical course deteriorates, clinicians tend to modify treatment regimens [5]. Though treatment dissatisfaction is frequently the culprit, it is often not directly considered or measured.

Psoriasis is a chronic inflammatory disease with a profound burden on physical health and quality of life [6-8]. Despite the availability of increasingly effective therapies, up to $40 \%$ of patients do not adhere to their treatments in the long term [9-16]. Though the reasons for this nonadherence are not well understood, treatment dissatisfaction is proposed to be key in driving patient behavior in long-term management $[13,15,17]$. Thus, treatment satisfaction in psoriasis has become a critical and emerging area of research [17-19].

Treatment satisfaction is defined as the degree to which the patients perceive that the treatment fulfills their health needs [20]. It is a reflection of the patient's experience with attributes of the therapeutic process, such as treatment duration, and therapeutic outcome, such as treatment benefit [21-28]. Clinicians and researchers have developed treatment satisfaction "instruments" or "measures" to evaluate patient experiences with the therapeutic process and outcome [20, 21]. Though these measures are important for psoriasis management, their utility hinges on their performance.

Measurement properties are established ways of evaluating the performance of instruments [29]. Measurement properties fall into 3 domains: reliability, defined as the degree to which instruments are free from error; validity, defined as the degree to which instruments measure the construct they intend to measure; and responsiveness, defined as the ability of instruments to detect change over time [29]. For example, an instrument may appear to be a valid measure of satisfaction; however, if repeat measures produce different scores, it is not reliable.

Incorporating treatment satisfaction instruments into therapeutic decision-making promotes patient-centered care and improves long-term compliance $[27,28]$. Determining the measurement properties of these instruments is paramount to the advancement of the field of dermatol- ogy, both in research and in clinical practice. This systematic review seeks to critically appraise the literature on measurement properties of treatment satisfaction instruments used in psoriasis.

\section{Materials and Methods}

See the online supplementary material (for all online suppl. materials and methods, online suppl. PROSPERO protocol, online suppl. PRISMA checklist, online suppl. stage 1 literature search strategy, and online suppl. stage 2 literature search strategy, see www.karger.com/doi/10.1159/000490413) [30-38, 45]. All steps of the study selection process are detailed in Figure 1.

\section{Results}

Ten studies met eligibility criteria. From these studies, 11 instruments were analyzed: 5 psoriasis-specific, 4 dermatology-specific, and 2 generic, nondermatologic measures. Table 1 presents an overview of the instruments. Table 2 presents each instrument's best evidence synthesis (online suppl. Table 1 and online suppl. Table 2). Table 3 presents the COnsensus-based Standards for the selection of health Measurement INstruments (COSMIN) results.

See the online supplementary material for detailed population characteristics (online suppl. Table 3), instrument characteristics (online suppl. Table 4), and study results (online suppl. Table 5).

Analysis of each instrument's measurement property data is discussed below.

\section{Psoriasis-Specific Measures}

REFlective evaLuation of psoriasis Efficacy of

Treatment and Severity (REFLETS)

Test-retest reliability achieved a "positive" rating due to an intraclass correlation coefficient $>0.70$ [39]. Internal consistency was rated "negative" due to a Cronbach's a $<0.70$ for one subdimension [39]. Due to "fair" COSMIN methodology, both ratings had "limited" levels of evidence.

REFLETS was relevant and comprehensive [39], resulting in a "positive" content validity rating. Its level of evidence was "strong" due to its "excellent" COSMIN methodology.

For structural validity, investigators did not report the variance explained by factors, resulting in an "indeterminate" rating [39]. Hypothesis testing revealed moderateto-high correlations with clinical severity and quality of 


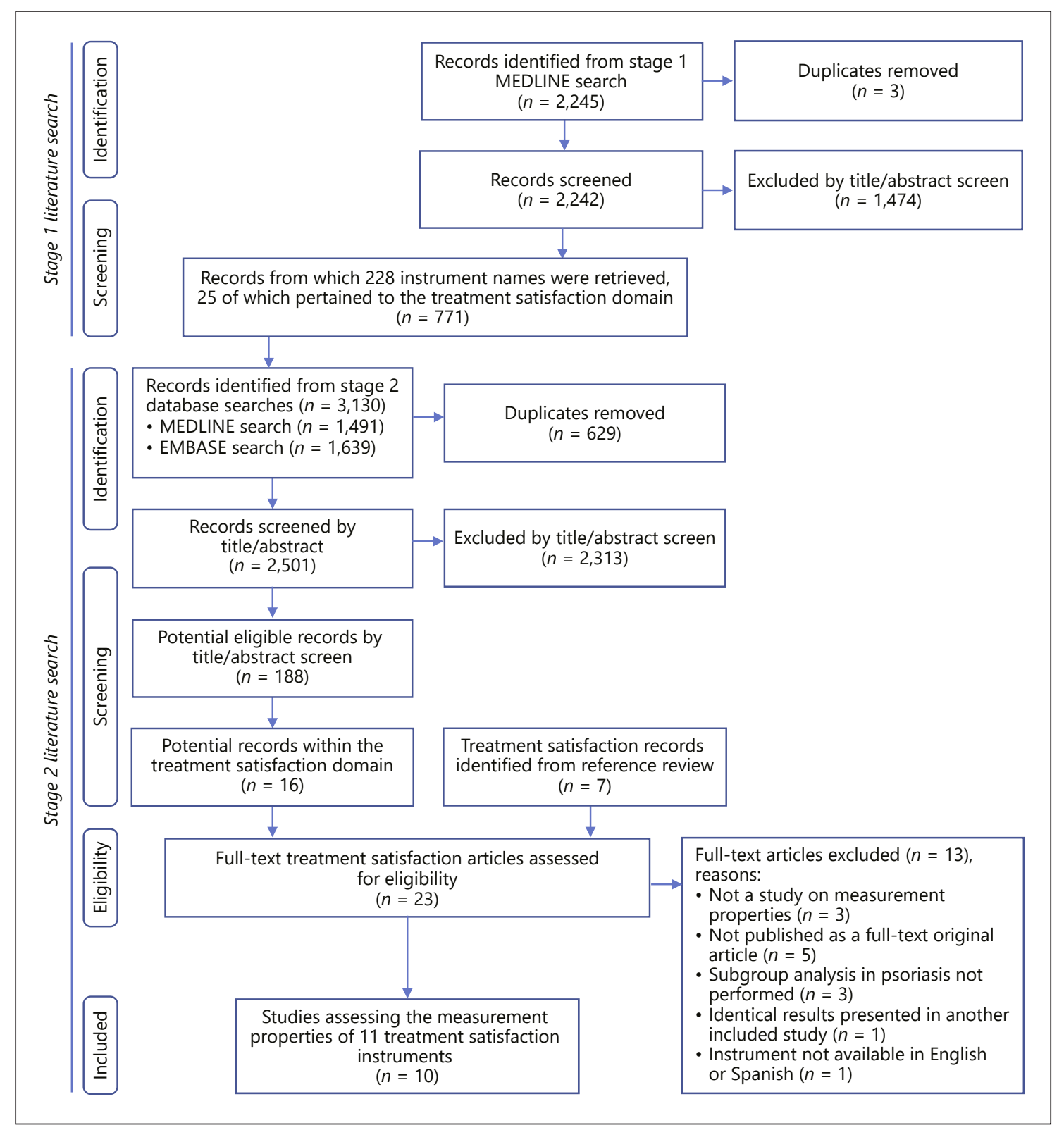

Fig. 1. Stage 1 and stage 2 flow diagram.

life measures [39]. However, this property was rated "indeterminate" because comparator instruments measured constructs other than treatment satisfaction. Because both properties had "fair" COSMIN methodology, their ratings had "limited" levels of evidence.

For responsiveness, investigators did not describe the comparator instruments' measurement properties, and their statistical methods were inappropriate [39]. Thus, it had "poor" COSMIN methodology and an "unknown" level of evidence.

Are Your Patients Satisfied? Treatment Satisfaction Measures in Psoriasis
Spanish Satisfaction With Treatment of Psoriasis Questionnaire (SSWTPQ)

SSWTPQ was comprehensive and relevant [40], resulting in a "positive" content validity rating. Due to "fair" COSMIN methodology, this rating had a "limited" level of evidence.

Internal consistency and test-retest reliability results revealed a Cronbach's $a>0.70$ and intraclass correlation coefficient $>0.70$ [31], respectively, which resulted in "positive" ratings. Due to both properties' "fair" 
Table 1. Overview of treatment satisfaction instruments

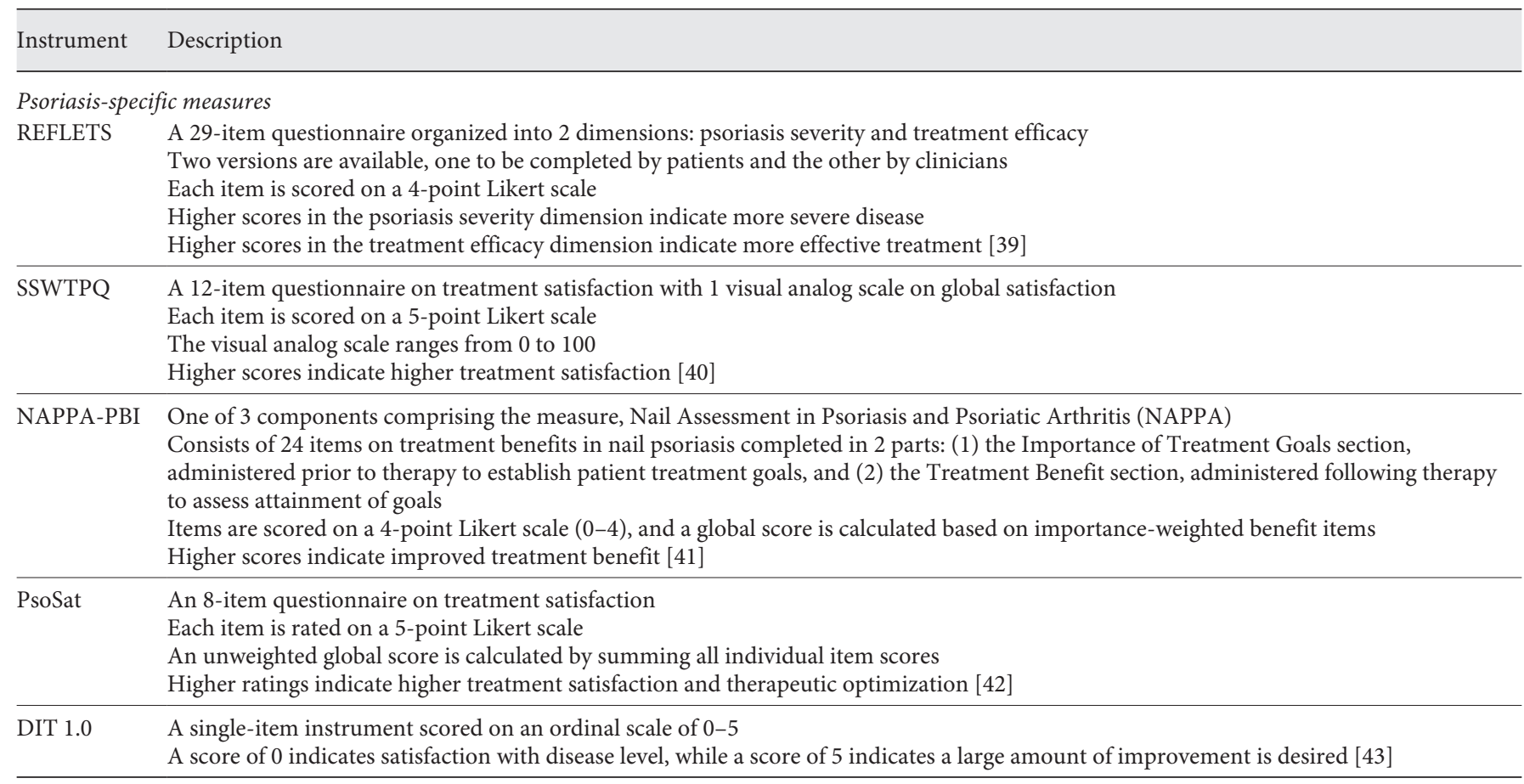

Dermatology-specific measures

PBI A 25-item questionnaire on treatment benefit with 5 subscales: (1) reducing social impairments; (2) reducing psychological impairments;

(3) reducing impairments due to therapy; (4) reducing physical impairments; (5) having confidence in healing

Consists of 2 questionnaires: the Patient Needs Questionnaire (PNQ), administered before therapy to establish patient treatment goals, and the Patient Benefit Questionnaire (PBQ), administered following therapy to assess attainment of goals

A global score is calculated by weighting extent of treatment goals attained according to patient-defined importance of those goals Higher scores indicate improved treatment benefit [44]

TTAQ A 40-item questionnaire for assessing factors influencing adherence in patients using topical therapy

Consists of 3 subscales: (1) patient benefit; (2) knowledge, communication, and relationship with physician; (3) satisfaction with treatment Scored on a 4-point Likert scale

Higher scores reflect the presence of favorable adherence-influencing factors

Of note, TTAQ and PPQ were initially developed as one instrument and were subsequently divided due to differences in administration TTAQ is designed to be administered more than once during the patient's treatment course [46]

PPQ A 10-item questionnaire for measuring patient preferences for topical therapy that contribute to adherence Scored on a 4-point Likert scale with higher scores reflecting the presence of favorable adherence-influencing patient preference factors Of note, TTAQ and PPQ were initially developed as one instrument and were subsequently divided due to differences in administration PPQ requires a single administration during the patient's treatment course [46]

Vehicle A 7-item question for measuring daytime and nighttime vehicle preferences for topical therapy

preference Each item is rated on a 7-point Likert scale from -3 (extremely unappealing) to +3 (extremely appealing)

score Higher scores indicate favorable vehicle preference [47]

Generic, nondermatologic measures

BMQ An 18-item questionnaire with 2 subscales: (1) Beliefs about Medicines Questionnaire in general (BMQ-General) and (2) Beliefs about Medicines Questionnaire for specific conditions (BMQ-Specific)

Subscales may be completed independently or in combination

Scored on a 5-point Likert scale with higher scores indicating stronger medication beliefs [48]

TSQM II An 11-item questionnaire with 4 subscales: (1) effectiveness; (2) side effects; (3) convenience; (4) overall satisfaction

Scored on a 5-point or 7-point Likert scale

Higher scores indicate increased treatment satisfaction [49]

REFLETS, REFlective evaLuation of psoriasis Efficacy of Treatment and Severity; SSWTPQ, Spanish Satisfaction With Treatment of Psoriasis Questionnaire; PsoSat, Psoriasis Satisfaction Questionnaire; NAPPA-PBI, Nail Assessment in Psoriasis and Psoriatic Arthritis - Patient Benefit Index; DIT, Desired Improvement Tool; PBI, Patient Benefit Index; PNQ, Patient Needs Questionnaire; PBQ, Patient Benefit Questionnaire; TTAQ, Topical Therapy Adherence Questionnaire; PPQ, Patient Preference Questionnaire; BMQ, Beliefs about Medicines Questionnaire; TSQM, Treatment Satisfaction Questionnaire for Medication. 
Table 2. Best evidence synthesis for the measurement properties of each instrument

\begin{tabular}{|c|c|c|c|c|c|c|c|}
\hline Instrument & $\begin{array}{l}\text { Internal } \\
\text { consistency }\end{array}$ & Reliability & $\begin{array}{l}\text { Content } \\
\text { validity }\end{array}$ & $\begin{array}{l}\text { Structural } \\
\text { validity }\end{array}$ & $\begin{array}{l}\text { Hypothesis } \\
\text { testing }\end{array}$ & $\begin{array}{l}\text { Cross- } \\
\text { cultural } \\
\text { validity }\end{array}$ & Responsiveness \\
\hline REFLETS [39] & - & + & +++ & ? (limited) & ? (limited) & 0 & $?$ \\
\hline SSWTPQ [40] & + & + & + & + & $?$ & 0 & $?$ \\
\hline NAPPA-PBI [41] & 0 & 0 & +++ & 0 & ? (limited) & a & $?$ \\
\hline DIT $1.0[43]$ & 0 & $?$ & 0 & 0 & ? (limited) & 0 & ? (limited) \\
\hline \multicolumn{8}{|l|}{ Dermatology-specific measures } \\
\hline PBI $[44]$ & - & 0 & 0 & 0 & ? (limited) & 0 & 0 \\
\hline TTAQ and PPQ [46] & $?$ & 0 & ++ & 0 & 0 & 0 & 0 \\
\hline Vehicle preference score [47] & 0 & 0 & 0 & 0 & $?$ & 0 & 0 \\
\hline
\end{tabular}

REFLETS, REFlective evaLuation of psoriasis Efficacy of Treatment and Severity; SSWTPQ, Spanish Satisfaction With Treatment of Psoriasis Questionnaire; PsoSat, Psoriasis Satisfaction Questionnaire; NAPPA-PBI, Nail Assessment in Psoriasis and Psoriatic Arthritis - Patient Benefit Index; DIT, Desired Improvement Tool; PBI, Patient Benefit Index; TTAQ, Topical Therapy Adherence Questionnaire; PPQ, Patient Preference Questionnaire; BMQ, Beliefs about Medicines Questionnaire; TSQM, Treatment Satisfaction Questionnaire for Medication. +++ or ---, positive or negative rating with strong level of evidence; ++ or --, positive or negative rating with moderate level of evidence; + or -, positive or negative rating with limited level of evidence; ? (strong), indeterminate rating with strong level of evidence; ? (moderate), indeterminate rating with moderate level of evidence; ? (limited), indeterminate rating with limited level of evidence; ?, unknown rating due to poor COSMIN methodological quality; 0 , no information. Criterion validity was not evaluated as no gold standard exists for measuring treatment satisfaction.

${ }^{a}$ Instrument translation was performed without formal cross-cultural validity assessments. Only studies that address measurement invariance between countries are considered true assessments of cross-cultural validity.

COSMIN methodology, these ratings achieved "limited" levels of evidence.

For structural validity, factors explained over $50 \%$ of the variance [40], resulting in a "positive" rating. Due to the property's "fair" COSMIN methodology, this rating had a "limited" level of evidence.

Hypothesis testing and responsiveness were assessed using the Psoriasis Area Severity Index (PASI) [40]. Because investigators did not describe PASI's measurement properties, both hypothesis testing and responsiveness received "poor" COSMIN methodology ratings and "unknown" levels of evidence.

Nail Assessment in Psoriasis and Psoriatic Arthritis Patient Benefit Index (NAPPA-PBI)

NAPPA-PBI was reliable and comprehensive [41], resulting in a "positive" content validity rating. This rating had a "strong" level of evidence due to its "excellent" COSMIN methodology.
Hypothesis testing revealed low correlations with clinical severity and quality of life instruments [41]. Because these instruments measured constructs other than treatment satisfaction and no a priori hypotheses were formulated, hypothesis testing was rated as "indeterminate." Due to "fair" COSMIN methodology, this rating achieved a "limited" level of evidence.

For responsiveness, investigators did not report score correlations [41]. Due to inappropriate statistics, its COSMIN methodology was "poor," resulting in an "unknown" level of evidence.

\section{Psoriasis Satisfaction Questionnaire (PsoSat)}

For internal consistency, investigators did not calculate a Cronbach's a for PsoSat subscales [42]. Consequently, it had "poor" COSMIN methodology and an "unknown" level of evidence. 
Table 3. Assessment of the quality of studies examining measurement properties: COSMIN results

\begin{tabular}{|c|c|c|c|c|c|c|c|c|}
\hline Instrument & Study & $\begin{array}{l}\text { Internal } \\
\text { consistency }\end{array}$ & Reliability & $\begin{array}{l}\text { Content } \\
\text { validity }\end{array}$ & $\begin{array}{l}\text { Structural } \\
\text { validity }\end{array}$ & $\begin{array}{l}\text { Hypothesis } \\
\text { testing }\end{array}$ & $\begin{array}{l}\text { Cross- } \\
\text { cultural } \\
\text { validity }\end{array}$ & $\begin{array}{l}\text { Respon- } \\
\text { siveness }\end{array}$ \\
\hline \multicolumn{9}{|l|}{ Psoriasis-specific measures } \\
\hline REFLETS & Gilet et al. [39] & fair & fair & excellent & fair & fair & - & poor \\
\hline SSWTPQ & Ribera et al. [40] & fair & fair & fair & fair & poor & - & poor \\
\hline NAPPA-PBI & Augustin et al. [41] & - & - & excellent & - & fair & a & poor \\
\hline DIT 1.0 & Zaghi et al. [43] & - & poor & - & - & fair & - & fair \\
\hline \multicolumn{9}{|c|}{ Dermatology-specific measures } \\
\hline PBI & Feuerhahn et al. [44] & fair & - & - & - & fair & - & - \\
\hline TTAQ and PPQ & Zschocke et al. [46] & poor & - & good & - & - & - & - \\
\hline Vehicle preference score & Housman et al. [47] & - & - & - & - & poor & - & - \\
\hline
\end{tabular}

REFLETS, REFlective evaLuation of psoriasis Efficacy of Treatment and Severity; SSWTPQ, Spanish Satisfaction With Treatment of Psoriasis Questionnaire; PsoSat, Psoriasis Satisfaction Questionnaire; NAPPA-PBI, Nail Assessment in Psoriasis and Psoriatic Arthritis - Patient Benefit Index; DIT, Desired Improvement Tool; PBI, Patient Benefit index; TTAQ, Topical Therapy Adherence Questionnaire; PPQ, Patient Preference Questionnaire; BMQ, Beliefs about Medicines Questionnaire; TSQM, Treatment Satisfaction Questionnaire for Medication. These ratings refer to the methodological quality of the studies. These ratings do not refer to the measurement properties themselves.

a Instrument translation was performed without formal cross-cultural validity assessments. Only studies that address measurement invariance between countries are considered true assessments of cross-cultural validity.

For content validity, investigators did not perform face validity assessments [42]. Thus, it had "poor" COSMIN methodology and an "unknown" level of evidence.

Structural validity was given a "positive" rating because the total variance explained by factors was $>50 \%$ [42]. This rating had a "strong" level of evidence due to its "excellent" COSMIN methodology.

Desired Improvement Tool (DIT) 1.0

The COSMIN methodology rating for test-retest reliability was "poor" due to the inappropriate time interval between assessments [43]. This resulted in an "unknown" level of evidence.

For hypothesis testing and responsiveness, the DIT correlated best with Body Surface Area (BSA), and scores were responsive to changes in BSA [43]. Because BSA is not a treatment satisfaction measure, both properties were rated "indeterminate." These ratings had a "limited" level of evidence due to "fair" COSMIN methodology.

\section{Dermatology-Specific Measures}

Patient Benefit Index (PBI)

Internal consistency was rated "negative" due to a Cronbach's $\alpha<0.70$ for one subscale [44]. However, unidimensionality was assessed in a previous study with a different patient population [45]. Thus, internal consistency had "fair" COSMIN methodology and its rating achieved a "limited"' level of evidence.

Hypothesis testing revealed low correlations with clinical severity and quality of life measures [44]. Because comparator instruments were not treatment satisfaction measures, hypothesis testing was rated "indeterminate." This rating achieved a "limited" level of evidence due to "fair" COSMIN methodology.

\section{Topical Therapy Adherence Questionnaire (TTAQ)} and Patient Preference Questionnaire (PPQ)

Investigators performed assessments before separating the original questionnaire into the two instruments, TTAQ and PPQ [46]. The original questionnaire was comprehensive and relevant to the psoriasis population, 
resulting in a "positive" content validity rating. This rating had a "moderate" level of evidence due to the property's "good" COSMIN methodology.

For internal consistency, factor analysis was not conducted and internal consistency statistics were not calculated for each subscale [46]. Consequently, it had "poor" COSMIN methodology and an "unknown" level of evidence.

\section{Vehicle Preference Score}

Content validity assessments involved an inadequate sample size [47]. Thus, it had "poor" COSMIN methodology and an "unknown" level of evidence.

\section{Generic, Nondermatologic Measures}

Beliefs about Medicines Questionnaire (BMQ)

BMQ lacked relevance and comprehensiveness among psoriasis patients [48]. Content validity was rated "positive" with a "strong" level of evidence due to its "excellent" COSMIN methodology.

Treatment Satisfaction Questionnaire for Medication (TSQM) Version II

Hypothesis testing showed weak-to-moderate correlations with quality of life and clinical severity instruments [49]. Because comparator instruments were not treatment satisfaction measures, hypothesis testing was rated "indeterminate." This rating had a "limited" level of evidence due to "fair" COSMIN methodology.

\section{Discussion}

This study provided a critical appraisal of the measurement properties of treatment satisfaction instruments used in psoriasis. Eleven instruments were analyzed.

Treatment satisfaction encompasses elements of the therapeutic process and therapeutic outcome [21-28]. In comparison, factors that are associated with treatment satisfaction include treatment preference, medication beliefs, and adherence $[27,28]$. Analyzed instruments exhibited significant heterogeneity in the constructs they measured - efficacy (REFLETS, NAPPA-PBI, PBI, DIT), satisfaction (SSWTQ, PsoSat, TSQM), preference (PPQ, vehicle preference score), adherence (TTAQ), and beliefs (BMQ). Due to limited consensus on how to measure treatment satisfaction, these instruments have been inconsistently used in clinical trials; this precludes comparison across trials and prevents clinicians and payers from assessing the true treatment value [32].

Are Your Patients Satisfied? Treatment Satisfaction Measures in Psoriasis
Additionally, the majority of analyzed instruments measure satisfaction across multiple therapeutic classes, including topical, oral, biologic, and phototherapy. Only the TTAQ, PPQ, and vehicle preference score were designed for use in a specific therapeutic class (topical). However, the literature informs us that attributes of the therapeutic process, such as route of administration, strongly influence adherence and satisfaction [21-28]. For example, therapeutic classes requiring multiple administrations, such as topical therapies and phototherapy, are associated with treatment dissatisfaction $[50,51]$. Thus, instruments for specific therapeutic classes are required to accurately measure satisfaction in clinical practice.

We identified shared limitations across studies. First, assessments were done with comparator instruments that measure constructs other than treatment satisfaction. By definition, "hypothesis testing" examines score correlations between instruments that measure the same construct [29]. Furthermore, investigators did not establish a priori hypotheses. This hinders meaningful discussion of the instruments' construct validity results. Finally, we detected important limitations involving interpretability of the instruments' scores, as no studies reported the minimal important change or floor and ceiling effects.

An evidence-based approach considering all measurement properties in a best evidence synthesis is essential to selecting the best instrument. Emphasis should be placed on the properties most important for the desired application [36]. Among the instruments, REFLETS, SSWTPQ, NAPPA-PBI, TTAQ, and PPQ were found to have appropriate content validity for use in the psoriasis population. Additionally, investigators may choose REFLETS or SSWTPQ for studies prioritizing instrument discrimination due to their positive reliability ratings [36].

Treatment satisfaction measures are crucial to psoriasis management. Dissatisfaction often results in nonadherence, which may be misinterpreted as treatment failure; this then leads to discontinuation of an otherwise effective therapy [5]. In addition, health care delivery systems and pharmaceutical industries use treatment satisfaction data to make decisions regarding cost-effectiveness and utility [20,52]. Thus, failure to adequately measure treatment satisfaction is detrimental to patient access to dermatologic care.

There is a critical need for standardized, validated treatment satisfaction measures in psoriasis. These measures identify treatment accessibility, treatment efficacy, treatments requiring modification, and patients at risk for nonadherence [53]. These measures additionally in- 
vite patients to participate in their care, creating a collaborative health care delivery model with improved therapeutic success $[27,28]$. This synthesis highlights the need for further research to better characterize the measurement properties of treatment satisfaction instruments and allow for standardized assessments across psoriasis clinical trials and clinical practice.

\section{Key Message}

Current literature provides insufficient evidence for identifying a single best treatment satisfaction instrument for psoriasis.

\section{Statement of Ethics}

Ethical clearance is not applicable as this review utilizes secondary, nonconfidential data from published studies and does not involve any direct patient interventions.

\section{Disclosure Statement}

Dr. Callis Duffin has served as a consultant, advisor and/or investigator for Amgen, Abbvie, Astra-Zeneca, Boehringer-Ingelheim, Bristol-Myers Squibb, Celgene, Eli Lilly, Janssen, Novartis, Pfizer, Regeneron, Sienna, Stiefel, UCB, and Xenoport. Dr. Garg has served as a consultant for Abbvie, Asana Biosciences, Janssen, Pfizer, and Merck, receiving honoraria. Also, he received research/ educational grants from AbbVie, Merck, and UCB. Dr. Gottlieb has served as a consultant/advisor for Amgen Inc., Astellas, Akros, Centocor (Janssen) Inc., Celgene Corp., Bristol Myers Squibb Co., Beiersdorf Inc., Abbott Labs (AbbVie), TEVA, Actelion, UCB, Novo Nordisk, Novartis, Dermipsor Ltd., Incyte, Pfizer, Canfite, Lilly, Coronado, Vertex, Karyopharm, CSL Behring Biotherapies for Life, Glaxo Smith Kline, Xenoport, Catabasis, Meiji Seika Pharma Co. Ltd., Takeda, Mitsubishi, Tanabe Pharma Development America Inc., Genentech, Baxalta, Kineta One, KPI Therapeutics, Crescendo Bioscience, Aclaris, Amicus, and Reddy Labs. Also, she received research/educational grants from Centocor (Janssen), Amgen, Abbott (AbbVie), Novartis, Celgene, Pfizer, Lilly, Levia, Merck, Xenoport, Dermira, and Baxalta. John Latella is a Patient Advocate for Boehringer Ingelheim and GsF. Dr. Merola has served as a consultant and/or investigator for Biogen IDEC, AbbVie, Eli Lilly, Novartis, Pfizer, Janssen, UCB, Samumed, Science 37, Celgene, Sanofi, Regeneron, Merck, and GSK. Dr. Armstrong has served as an investigator and/or consultant for Amgen, AbbVie, Janssen, Lilly, Pfizer, Celgene, and Merck.

\section{References}

1 Brody DS, Miller SM, Lerman CE, Smith DG, Caputo GC: Patient perception of involvement in medical care: relationship to illness attitudes and outcomes. J Gen Intern Med 1989;4:506-511.

2 Taylor TR: Understanding the choices that patients make. J Am Board Fam Pract 2000; 13:124-133.

3 Weaver M, Patrick DL, Markson LE, Martin D, Frederic I, Berger M: Issues in the measurement of satisfaction with treatment. Am J Manag Care 1997;3:579-594.

4 Dunbar-Jacob J, Erlen JA, Schlenk EA, Ryan CM, Sereika SM, Doswell WM: Adherence in chronic disease. Annu Rev Nurs Res 2000;18: 48-90.

5 Dunbar-Jacob J, Mortimer-Stephens MK: Treatment adherence in chronic disease. J Clin Epidemiol 2001;54(suppl 1):S57-S60.

6 De Korte J, Sprangers MA, Mombers FM, Bos JD: Quality of life in patients with psoriasis: a systematic literature review. J Investig Dermatol Symp Proc 2004;9:140-147.

7 Kimball AB, Gladman D, Gelfand JM, Gordon K, Horn EJ, Korman NJ, Korver G, Krueger GG, Strober BE, Lebwohl MG: National Psoriasis Foundation clinical consensus on psoriasis comorbidities and recommendations for screening. J Am Acad Dermatol 2008;58:1031-1042.

8 Krueger G, Koo J, Lebwohl M, Menter A, Stern RS, Rolstad T: The impact of psoriasis on quality of life: results of a 1998 National Psoriasis Foundation patient-membership survey. Arch Dermatol 2001;137:280-284.

9 Meyer N, Paul C, Feneron D, Bardoulat I, Thiriet C, Camara C, Sid-Mohand D, Le Pen C, Ortonne JP: Psoriasis: an epidemiological evaluation of disease burden in 590 patients. J Eur Acad Dermatol Venereol 2010;24:10751082.

10 Augustin M, Holland B, Dartsch D, Langenbruch A, Radtke MA: Adherence in the treatment of psoriasis: a systematic review. Dermatology 2011;222:363-374.

11 Feldman SR, Evans C, Russell MW: Systemic treatment for moderate to severe psoriasis: estimates of failure rates and direct medical costs in a north-eastern US managed care plan. J Dermatolog Treat 2005;16:37-42.

12 Horn EJ, Fox KM, Patel V, Chiou CF, Dann F, Lebwohl M: Are patients with psoriasis undertreated? Results of National Psoriasis Foundation survey. J Am Acad Dermatol 2007;57:957-962.

13 Nijsten T, Margolis DJ, Feldman SR, Rolstad T, Stern RS: Traditional systemic treatments have not fully met the needs of psoriasis patients: results from a national survey. J Am Acad Dermatol 2005;52:434-444.

14 Richards HL, Fortune DG, O’Sullivan TM, Main CJ, Griffiths CE: Patients with psoriasis and their compliance with medication. J Am Acad Dermatol 1999;41:581-583.
15 Stern RS, Nijsten T, Feldman SR, Margolis DJ, Rolstad T: Psoriasis is common, carries a substantial burden even when not extensive, and is associated with widespread treatment dissatisfaction. J Investig Dermatol Symp Proc 2004;9:136-139.

16 Yeung H, Wan J, Van Voorhees AS, Callis Duffin K, Krueger GG, Kalb RE, Weisman JD, Sperber BR, Brod BA, Schleicher SM, Bebo BF Jr, Shin DB, Troxel AB, Gelfand JM: Patientreported reasons for the discontinuation of commonly used treatments for moderate to severe psoriasis. J Am Acad Dermatol 2013; 68:64-72.

17 Armstrong AW, Robertson AD, Wu J, Schupp C, Lebwohl MG: Undertreatment, treatment trends, and treatment dissatisfaction among patients with psoriasis and psoriatic arthritis in the United States: findings from the National Psoriasis Foundation surveys, 2003-2011. JAMA Dermatol 2013;149:11801185.

18 Lecluse LL, Tutein Nolthenius JL, Bos JD, Spuls PI: Patient preferences and satisfaction with systemic therapies for psoriasis: an area to be explored. Br J Dermatol 2009;160:13401343.

19 Tan JK, Wolfe BJ, Bulatovic R, Jones EB, Lo AY: Critical appraisal of quality of clinical practice guidelines for treatment of psoriasis vulgaris, 2006-2009. J Invest Dermatol 2010; 130:2389-2395. 
20 Shikiar R, Rentz AM: Satisfaction with medication: an overview of conceptual, methodologic, and regulatory issues. Value Health 2004;7:204-215.

21 Ito K, Imafuku S, Nakayama J: Therapeutic preferences are different in psoriatic and atopic dermatitis patients: a questionnairebased study. J Dermatol 2013;40:292-294.

22 Kromer C, Peitsch WK, Herr R, Schmieder A, Sonntag D, Schaarschmidt ML: Treatment preferences for biologicals in psoriasis: experienced patients appreciate sustainability. J Dtsch Dermatol Ges 2017;15:189-200.

23 Kromer C, Schaarschmidt ML, Schmieder A, Herr R, Goerdt S, Peitsch WK: Patient preferences for treatment of psoriasis with biologicals: a discrete choice experiment. PLoS One 2015;10:e0129120.

24 Schaarschmidt ML, Herr R, Gutknecht M, Wroblewska K, Gerdes S, Sticherling M, Augustin M, Peitsch WK: Patients' and physicians' preferences for systemic psoriasis treatments: a nationwide comparative discrete choice experiment (PsoCompare). Acta Derm Venereol 2018;98:200-205.

25 Schaarschmidt ML, Kromer C, Herr R, Schmieder A, Goerdt S, Peitsch WK: Treatment satisfaction of patients with psoriasis. Acta Derm Venereol 2015;95:572-578.

26 Torbica A, Fattore G, Ayala F: Eliciting preferences to inform patient-centred policies: the case of psoriasis. Pharmacoeconomics 2014;32:209-223.

27 Umar N, Schaarschmidt M, Schmieder A, Peitsch WK, Schollgen I, Terris DD: Matching physicians' treatment recommendations to patients' treatment preferences is associated with improvement in treatment satisfaction. J Eur Acad Dermatol Venereol 2013;27: 763-770.

28 Umar N, Litaker D, Schaarschmidt ML, Peitsch WK, Schmieder A, Terris DD: Outcomes associated with matching patients' treatment preferences to physicians' recommendations: study methodology. BMC Health Serv Res 2012;12:1.

29 Mokkink LB, Terwee CB, Patrick DL, Alonso J, Stratford PW, Knol DL, Bouter LM, de Vet HC: The COSMIN study reached international consensus on taxonomy, terminology, and definitions of measurement properties for health-related patient-reported outcomes. J Clin Epidemiol 2010;63:737-745.

30 Callis Duffin K, Merola JF, Christensen R, Latella J, Garg A, Gottlieb AB, Armstrong AW: Identifying a core domain set to assess psoriasis in clinical trials: a combined Delphi Consensus Survey from the International Dermatology Outcome Measures Initiative. JAMA Dermatol 2018, Epub ahead of print.

31 Elman SA, Merola JF, Armstrong AW, et al: The International Dermatology Outcome
Measures (IDEOM) initiative: a review and update. J Drugs Dermatol 2017;16:119-124.

32 Gottlieb AB, Levin AA, Armstrong AW, Duffin KC, Latella J, Garg A, Gottlieb AB; International Dermatology Outcome Measures Group: Formation of patient-centered outcome measures in dermatology. J Am Acad Dermatol 2015;72:345-348.

33 Merola JF, Armstrong AW, Saraiya A, Latella J, Garg A, Callis Duffin K, Gottlieb AB: International Dermatology Outcome Measures Initiative as applied to psoriatic disease outcomes: an update. J Rheumatol 2016;43:959960.

34 Mokkink LB, Terwee CB, Patrick DL, Alonso J, Stratford PW, Knol DL, Bouter LM, de Vet HC: The COSMIN checklist for assessing the methodological quality of studies on measurement properties of health status measurement instruments: an international Delphi study. Qual Life Res 2010;19:539-549.

35 Terwee CB, Mokkink LB, Knol DL, Ostelo RW, Bouter LM, de Vet HC: Rating the methodological quality in systematic reviews of studies on measurement properties: a scoring system for the COSMIN checklist. Qual Life Res 2012;21:651-657.

36 Terwee CB, Bot SD, de Boer MR, van der Windt DA, Knol DL, Dekker J, Bouter LM, de Vet HC: Quality criteria were proposed for measurement properties of health status questionnaires. J Clin Epidemiol 2007;60:34-42.

37 Terwee CB: Protocol for systematic reviews of measurement properties. COSMIN, 2011. www.cosmin.nl.

38 Furlan AD, Pennick V, Bombardier C, van Tulder M: 2009 updated method guidelines for systematic reviews in the Cochrane Back Review Group. Spine (Phila Pa 1976) 2009;34: 1929-1941.

39 Gilet H, Roborel de Climens A, Arnould B, Bachelez H, Bagot M, Beaulieu P, Joly P, Jullien D, Le Maître M, Ortonne JP, Paul C, Thibout E: Development and psychometric validation of the REFlective evaLuation of psoriasis Efficacy of Treatment and Severity (REFLETS) questionnaire: a common measure of plaque-type psoriasis severity and treatment efficacy for patients and clinicians. J Eur Acad Dermatol Venereol 2015;29:498-506.

40 Ribera M, Daudén E, Puig L, Briones VG, Herranz JM, Bordas X, Vanaclocha F: Design and validation of a questionnaire to measure treatment satisfaction in patients with moderate-to-severe psoriasis: The NEODERMA study. Actas Dermo-Sifiliograficas 2011;102: 28-38.

41 Augustin M, Blome C, Costanzo A, Dauden E, Ferrandiz C, Girolomoni G, Gniadecki R, Iversen L, Menter A, Michaelis-Wittern K, Morita A, Nakagawa H, Reich K: Nail assessment in psoriasis and psoriatic arthritis
(NAPPA): development and validation of a tool for assessment of nail psoriasis outcomes. Br J Dermatol 2014;170:591-598.

42 Radtke MA, Spehr C, Reich K, Rustenbach SJ, Feuerhahn J, Augustin M: Treatment satisfaction in psoriasis: development and use of the PsoSat patient questionnaire in a cross-sectional study. Dermatology 2016;232:334-343.

43 Zaghi D, Weir C, Ying J, Carlin C, Greene T, DeShazo R, Callis Duffin K, Krueger GG: Desired Improvement Tool (DIT): a tool to assess desire for improvement in psoriasis patients. J Dermatolog Treat 2016;27:27-30.

44 Feuerhahn J, Blome C, Radtke M, Augustin M: Validation of the patient benefit index for the assessment of patient-relevant benefit in the treatment of psoriasis. Arch Dermatol Res 2012;304:433-441.

45 Blome C, Augustin M, Behechtnejad J, Rustenbach SJ: Dimensions of patient needs in dermatology: subscales of the patient benefit index. Arch Dermatol Res 2011;303:1117.

46 Zschocke I, Mrowietz U, Lotzin A, Karakasili E, Reich K: Assessing adherence factors in patients under topical treatment: development of the Topical Therapy Adherence Questionnaire (TTAQ). Arch Dermatol Res 2014;306: 287-297.

47 Housman TS, Mellen BG, Rapp SR, Fleischer $A B$ Jr, Feldman SR: Patients with psoriasis prefer solution and foam vehicles: a quantitative assessment of vehicle preference. Cutis 2002;70:327-332.

48 Thorneloe RJ, Griffiths CE, Ashcroft DM, Cordingley L: The challenges of assessing patients' medication beliefs: a qualitative study. BMC Health Serv Res 2017;17:119.

49 Duffin KC, Yeung H, Takeshita J, Krueger GG, Robertson AD, Troxel AB, Shin DB, Van Voorhees AS, Gelfand JM: Patient satisfaction with treatments for moderate-to-severe plaque psoriasis in clinical practice. Br J Dermatol 2014;170:672-680.

50 Feldman SR, Camacho FT, Krejci-Manwaring J, Carroll CL, Balkrishnan R: Adherence to topical therapy increases around the time of office visits. J Am Acad Dermatol 2007;57: 81-83.

51 Ahn CS, Culp L, Huang WW, Davis SA, Feldman SR: Adherence in dermatology. J Dermatolog Treat 2017;28:94-103.

52 Atkinson MJ, Sinha A, Hass SL, Colman SS, Kumar RN, Brod M, Rowland CR: Validation of a general measure of treatment satisfaction, the Treatment Satisfaction Questionnaire for Medication (TSQM), using a national panel study of chronic disease. Health Qual Life Outcomes 2004;2:12.

53 Jackson JL, Chamberlin J, Kroenke K: Predictors of patient satisfaction. Soc Sci Med 2001; 52:609-620.
Are Your Patients Satisfied? Treatment Satisfaction Measures in Psoriasis
Dermatology 2018;234:157-165

DOI: $10.1159 / 000490413$ 